\title{
Born or made - Can interdisciplinary and intersectoral doctorate education create institutional entrepreneurs? A systematic review
}

\author{
Niamh Leniston, Nicola Mountford
}

Maynooth University, Ireland.

\begin{abstract}
Solving grand societal challenges such as equitable healthcare provision and climate change will require institutional entrepreneurs - people who can challenge prevailing regulations, behaviors, and ways of thinking. As the pinnacle of educational achievement, the doctoral degree should be the fire in which such fledgling institutional entrepreneurs are forged. Doctoral education has, however, been criticized as overspecialized and divorced from reality. We systematically review the doctoral education literature in our search for doctoral education programs that challenge institutional norms by bridging sectoral and disciplinary divides. We ask whether such programs can help to nurture institutionally entrepreneurial researchers. We find that students must manage ambiguous identities and wide networks but that such programs have the potential to equip them for both sense-making and sensegiving activities of institutional entrepreneurship.
\end{abstract}

Keywords: Doctoral education; institutional entrepreneurship; intersectoral; interdisciplinary. 


\section{Introduction}

Institutional entrepreneurs are essential to the solving of many of modern society's grand challenges such as equitable healthcare provision or climate change as they "spearhead collective attempts to infuse new beliefs, norms, and values into social structures, thus creating discontinuities in the world of organizations." (Rao et al., 2000: 239). They view the world through various lenses and bring otherwise disconnected ideas and values together. Institutional entrepreneurs wield business knowledge alongside political sense and an ability to anticipate reception from multiple angles (Dorado, 2005). They deploy an array of skills: analytic, empathetic, framing, translational, organizational, tactical, and timing (Fohim, 2020). Understanding different perspectives results in credibility and trust, leading to strong social networks which can be merged to achieve their goals (Battilana and Casciaro, 2012).

Traditionally, universities have been hailed as the institutional center of education and research in society. Recently this perspective has shifted to include a new role of intersectoral collaboration and knowledge sharing (Cardoso et al., 2019) increasing pressure to contribute to innovation and industrial competitiveness (Haapakorpi, 2017). The doctorate, despite being the highest form of educational attainment, has faced criticism for its incompatibility with demands of the modern workplace (Celis and Acosta, 2016). Missing transferable skills, overspecialization and a lack of real-world experience and practical knowledge have all been identified as issues with traditional doctorate programs (Cui and Harshman, 2020).

Two approaches have been taken to reform doctorate education. The first is interdisciplinarity, where "scholars work jointly on a common problem with the intention of transferring knowledge from one discipline to another" (Kemp and Nurius, 2015: 134). This differs from the traditional isolation of the student within doctoral education, instead focusing on collaboration and boundary-spanning (Balleisen and Wisdom, 2018). The second approach is intersectorality, or industrial PhDs, encouraged by governmental innovation policies linking industry and education (Celis and Acosta, 2016). The student typically takes on dual roles of researcher and practitioner with research relevant to both academia and industry (Cardoso et al., 2019). The skills, knowledge, and boundary-spanning activities encouraged through such programs are key to institutional entrepreneurship. Thus, this review asks: Is it possible to train an institutional entrepreneur?

\section{Methodology}

We conducted a systematic review of interdisciplinary and intersectoral doctorate education literature following Aguinis et al.'s (2018) steps to ensure inferential reproducibility: (1) identification of sources, (2) screening to narrow results, (3) applying eligibility criteria and, (4) confirmation of sources to be reviewed in full. We applied four inclusion and exclusion criteria to further develop the standard for review (Rhaiem et al., 2019) (see table 1). 
Table 1. Exclusion criteria for systematic review

\begin{tabular}{cccc}
\hline Criteria & Inclusion & Exclusion & Rationale \\
\hline Language & English & $\begin{array}{c}\text { Not available in } \\
\text { English }\end{array}$ & Authors' ability to analyse \\
Content & $\begin{array}{l}\text { Relevant to } \\
\text { doctoral education }\end{array}$ & $\begin{array}{c}\text { Irrelevant to doctoral } \\
\text { education }\end{array}$ & $\begin{array}{c}\text { Relevancy to research } \\
\text { question }\end{array}$ \\
Peer & Peer reviewed & Non-peer reviewed & journal articles \\
Review & journal articles & Information is from a \\
reliable source & Database & Scopus and & Databases not included in \\
Selection & ProQuest & Scopus or ProQuest & $\begin{array}{c}\text { Both databases provide } \\
\text { wide disciplinary coverage }\end{array}$ \\
\hline
\end{tabular}

Two electronic databases were searched for this review: ProQuest and Scopus, using three searches between the end of October to the end of November 2020:

1. "interdisciplinary" AND "doctora* education": Abstract searches returned 107 (Scopus) and 199 (ProQuest) results. Language and source checks reduced this to 34 (Scopus) and 64 (ProQuest). Eligibility assessment through reading of abstracts and introductions eliminated 4 (Scopus) and 23 (ProQuest). 13 duplicates were removed. 7 articles were unavailable to access and further reading resulted in the removal of 3 further articles. This left 48 for review.

2. “intersectoral" AND "doctora* education": Abstract searches returned 9 (Scopus) and 0 (ProQuest). All failed to meet eligibility criteria.

3. "university industry collaboration" and "doctora* education": Abstract searches returned 22 articles. 5 duplicates were removed, leaving 17. 1 article was removed due to lack of access and a second lacked useful information upon reading. 15 articles were therefore added to the previous list giving 63 articles for review.

Approximately $57 \%$ of the articles were published in education journals, though there were also publications in healthcare (14.3\%), STEM (14.3\%), management $(9.5 \%)$ and other/multidisciplinary journals (6.35\%). We used the Gioia method (Gioia et al., 2013), to inductively analyze the articles using NVivo qualitative data analysis software.

\section{Findings}

We identify those elements of intersectoral and interdisciplinary doctoral education that a) map onto characteristics of institutional entrepreneurs as identified in that literature; and b) challenge existing institutions - cognitive, normative and regulatory. 


\subsection{Skills \& networks for institutional entrepreneurship}

Although 'soft skills' are highly sought after, little attention is given to their development within traditional doctorate programmes. Employers demands to address the mismatch between industry needs and doctoral skills (Cardoso et al., 2019) mean, however, that many programs now addressing the issue of transferable skills (Santos et al., 2020). Since transferable skills apply across disciplinary and professional boundaries (Haapakorpi, 2017) they are crucial to the development of institutional entrepreneurs enabling communication, flexibility, leadership, teamwork, planning, organization, management, and problem solving (Cui and Harshman, 2020).

Owen Smith \& Powell (2008) describe how ambiguous identities and multiple networks create conditions conducive to institutional entrepreneurship. While mentors and supervisors may provide access to sectoral or disciplinary networks (Caliskan and Holley, 2017), networking outside the home discipline can lead to an appreciation of different epistemologies (Bosque Pérez et al., 2016). Such interactions may also extend strong ties beyond disciplinary boundaries with access to different perspectives (Mountford et al., 2019).

\subsection{Challenges to existing institutions}

\subsubsection{Cognitive challanges}

Research cultures are the set of beliefs, norms, and values that exist within a particular discipline or research institution (Kunttu et al., 2018). Humility and respect are key to breaking down the barriers of research cultures (Carr et al., 2018). It can be easy to misinterpret others with whom we do not share a common goal or value, so a broad understanding of other disciplines and understanding their viewpoints is important (Bosque Pérez et al., 2016; Cui and Harshman, 2020). A shared vision brings interdisciplinary team members closer together and broadens researchers' perspectives (Bosque Pérez et al., 2016). Individual students can then see how their own work can benefit other disciplines and begin to identify their own opportunities for collaboration (Kiley and Halliday, 2019).

Curricular activities that break down such cognitive barriers include seminars and mini presentations to share research ideas and methods (Kiley and Halliday, 2019). Asking students to discuss the strengths and weaknesses of their main research discipline as a class activity, fosters appreciation of the uses of various epistemologies and methodologies (Carr et al., 2018). Self-reflective surveys were issued during a seminar titled 'Philosophical Issues in Interdisciplinary Research' to challenge students to think critically about their assumptions going into the course (Bosque-Pérez et al., 2016). Another example includes a workshop titled 'Finding our way: interprofessional connected health education' that directly asked students to think ahead about what barriers or misunderstandings may occur in their interdisciplinary work and how might they overcome them (Chouvarda et al., 2019). 
Less formal efforts include low stakes interactions such as group meals (Balleisen and Wisdom., 2018). The relaxed nature of such interactions opens up discussion without fear of judgement (Kiley and Halliday, 2019), building trust and respect (Carr et al., 2018). Relaxed students are more creative and open-minded (Chouvarda et al., 2019). Ideally, a program wishing to foster collaboration would prioritize both formal and informal interaction opportunities to develop personal and collective skills (Caliskan and Holley, 2017).

Mentors and supervisors can either question or reinforce cognitive norms. They influence how students see their work and the world around them (Hammel et al., 2015). Interdisciplinary or intersectoral students may have two or more supervisors, scrutinizing their research from multiple perspectives (Bosque Pérez et al., 2016; Carr et al., 2018). Intersectoral programs may have a professional supervisor in addition to a peer mentor (Caliskan and Holley, 2017) where mentors hold a more informal type of relationship with the student that can facilitate further questioning of norms.

\subsubsection{Normative challenges}

Dorado (2005) defines the agency required for institutional entrepreneurship as "the motivation and the creativity that drive actors to break away from scripted patterns of behaviour" (p. 388). Such scripted patterns include communication preferences across sectors e.g. academics prefer written communication while industry favors oral communication (Cui and Harshman, 2020). Efforts to move beyond such norms can, however, incur costs. Digital communication, for example, is consistent in its reception by interdisciplinary students regardless of background with blogs and social media allowing students to keep in touch and share information (Balleisen and Wisdom., 2018; Mountford et al., 2019). However, a lack of physical presence in collaboration has led to decreasing quality of relationships and trust, alongside reduced networking opportunities (Carr et al., 2018).

Supervisors can struggle where students deviate from their own norms often worrying whether they can handle a student that takes a direction unfamiliar to them. Busy schedules and lack of personal fit can exacerbate such difficulties (Caliskan and Holley, 2017). A faculty training program may better prepare supervisors for working with others in interdisciplinary or intersectoral contexts (Bosque-Pérez et al., 2016). Ideal supervisory traits to deal with challenges to behavioural and cognitive norms include open-mindedness, curiosity and being receptive to having one's biases challenged (Kiley and Halliday, 2019).

\subsubsection{Regulatory challenges}

The organizational and professional institutions of academic life may regulate against those who challenge them. Organizational structures in universities typically separate disciplines into different departments with little encouragement or effort made to develop communication across departments, leading to knowledge separation and segregation rather 
than integration (Donina et al., 2017). Universities give quicker graduation and promotion to disciplinary, rather than interdisciplinary work (Golembiewskih et al., 2018).

\section{Discussion}

Identity directly influences a student's sense of belonging (Caliskan and Holley, 2017). When identity is unclear, students can struggle to identify and market their own capabilities (Holley, 2018). In an interdisciplinary environment where boundaries are broken down, this is especially important as: "identity development and socialization ... enable emergent interdisciplinary scholars to develop strong connections with multiple communities that align with their emergent professional identities" (Holley, 2018: 124). Building a strong research community within interdisciplinary programs is key, as it can improve student confidence and sense of belonging (Caliskan and Holley, 2017; Kiley and Halliday, 2018). This may allow students to become institutional entrepreneurs as they combine a level of ambiguity of identity with strong ties in wide networks (Owen Smith \& Powell, 2008) to make sense of multiple inputs and give sense to multiple communities.

\subsection{Sensemaking versus Sensegiving}

Institutional entrepreneurs adopt one of three forms of agency: routine, strategic or sensemaking (Dorado, 2005). Past studies have focused on the sensemaking abilities of institutional entrepreneurs (Dorado, 2005), however, Santos and Eisenhardt (2009) suggest that institutional entrepreneurs also play a role in 'sensegiving' or claiming, that is the act of taking familiar information and presenting it with new meaning. Storytelling is particularly useful at conveying meaning to these audiences (Santos and Eisenhardt, 2009). This concept of sensegiving and storytelling echoes interdisciplinary programs' focus on teaching new methodologies and promoting qualitative research, particularly to STEM students.

Intersectoral or interdisciplinary social networks may be more or less accessible, depending on how structured or "opportunity hazy" the field is (Dorado, 2005; 397). Doctoral students who work with others from varying disciplines learn how to spot opportunities for later collaboration and value the opportunities to build social networks beyond their home discipline, department and institution (Balleisen and Wisdom, 2018). Social capital accumulated through participation can potentially aid in later boundary-spanning (Mountford et al., 2019) and improve ability to give sense to a variety of audiences.

Our review indicates that intersectoral and interdisciplinary doctorate programs may have the potential to forge institutional entrepreneurs who can overcome the cognitive, normative and regulatory barriers to solving some of society's greatest challenges. There is, however, an imbalance in the academic literature on interdisciplinarity and intersectorality. Despite the increasing involvement of stakeholders in collaborative programs, the concept of 
intersectorality at doctorate level is still lacking. Future research may require looking beyond academic literature to other documents from grey literature, given the involvement from industry and potential policy-makers in shaping these doctoral programs.

\section{References}

Aguinis, H., Ramani, R. S., \& Alabduljader, N. (2018). What you see is what you get? Enhancing methodological transparency in management research. Academy of Management Annals, 12(1), 83-110.

Balleisen, E. J., \& Wisdom, M. L. M. (2018). Rethinking Graduate Education in the Humanities. Change: The Magazine of Higher Learning, 50(5), 46-52.

Battilana, J., \& Casciaro, T. (2012). Change agents, networks, and institutions: A contingency theory of organizational change. Academy of Management Journal, 55(2), 381-398.

Bosque-Pérez, N. A., Klos, P. Z., Force, J. E., Waits, L. P., Cleary, K., Rhoades, P., ... \& Holbrook, J. D. (2016). A pedagogical model for team-based, problem-focused interdisciplinary doctoral education. BioScience, 66(6), 477-488.

Cardoso, S., Tavares, O., \& Sin, C. (2019). Can you judge a book by its cover? Industrial doctorates in Portugal. Higher Education, Skills and Work-Based Learning.

Caliskan, O., \& Holley, K. (2017). Doctoral student support programs in diverse national contexts. Journal of Applied Research in Higher Education.

Carr, G., Loucks, D. P., \& Blöschl, G. (2018). Gaining insight into interdisciplinary research and education programmes: A framework for evaluation. Research Policy, 47(1), 35-48. Celis, J., \& Acosta, O. (2016). Industrial Ph. D. Programs for the Strengthening of the

Industry's Production of Innovation in Colombia. Innovar, 26(62), 129-146.

Chouvarda, I., Mountford, N., Trajkovik, V., Loncar-Turukalo, T., \& Cusack, T. (2019). Leveraging interdisciplinary education toward securing the future of connected health research in Europe: qualitative study. Journal of Medical Internet Research, 21(11), e14020.

Cui, Q., \& Harshman, J. (2020). Qualitative investigation to identify the knowledge and skills that US-trained doctoral chemists require in typical chemistry positions. Journal of Chemical Education, 97(5), 1247-1255.

Donina, D., Seeber, M., \& Paleari, S. (2017). Inconsistencies in the governance of interdisciplinarity: the case of the Italian higher education system. Science and Public Policy, 44(6), 865-875.

Dorado, S. (2005). Institutional entrepreneurship, partaking, and convening. Organization Studies, 26(3), 385-414.

Fohim, E. (2019). Institutional entrepreneurs' skills: A multi-dimensional concept.

In Microfoundations of Institutions. Emerald Publishing Limited.

Gioia, D. A., Corley, K. G., \& Hamilton, A. L. (2013). Seeking qualitative rigor in inductive research: Notes on the Gioia methodology. Organizational research methods, 16(1), $15-$ 31.

Golembiewski, E. H., Holmes, A. M., Jackson, J. R., Brown-Podgorski, B. L., \& Menachemi, 
N. (2018). Interdisciplinary dissertation research among public health doctoral trainees, 2003-2015. Public Health Reports, 133(2), 182-190.

Haapakorpi, A. (2017). Doctorate holders outside the academy in Finland: Academic engagement and industry-specific competence. Journal of Education and Work, 30(1), 53-68.

Hammel, J., Magasi, S., Mirza, M. P., Fischer, H., Preissner, K., Peterson, E., \& SuarezBalcazar, Y. (2015). A scholarship of practice revisited: Creating community-engaged occupational therapy practitioners, educators, and scholars. Occupational therapy in health care, 29(4), 352-369.

Holley, K. A. (2018). The longitudinal career experiences of interdisciplinary neuroscience $\mathrm{PhD}$ recipients. The Journal of Higher Education, 89(1), 106-127.

Kemp, S. P., \& Nurius, P. S. (2015). Preparing emerging doctoral scholars for transdisciplinary research: A developmental approach. Journal of teaching in social work, 35(1-2), 131-150.

Kiley, M., \& Halliday, D. P. (2019). Candidate and supervisor experiences of doctoral study in a structured, interdisciplinary training environment. Innovations in Education and Teaching International, 56(5), 663-674.

Kunttu, L., Huttu, E., \& Neuvo, Y. (2018). How doctoral students and graduates can facilitate boundary spanning between academia and industry. Technology Innovation Management Review, 8(6), 48-54.

Mountford, N., Coleman, M., Kessie, T., \& Cusack, T. (2020). Interdisciplinary doctoral research networks: enhancers and inhibitors of social capital development. Studies in Higher Education, 45(12), 2558-2573.

Owen-Smith, J., \& Powell, W. W. (2008). Networks and institutions. The Sage handbook of organizational institutionalism, 596-623.

Rao, H., Morrill, C., \& Zald, M. N. (2000). Power plays: How social movements and collective action create new organizational forms. Research in organizational behavior, 22, 237-281.

Rhaiem, K., \& Amara, N. (2019). Learning from innovation failures: A systematic review of the literature and research agenda. Review of Managerial Science, 1-46.

Santos, F. M., \& Eisenhardt, K. M. (2009). Constructing markets and shaping boundaries: Entrepreneurial power in nascent fields. Academy of Management Journal, 52(4), 643671. 